Article

\title{
Performance of Polyester-Based Electrospun Scaffolds under In Vitro Hydrolytic Conditions: From Short-Term to Long-Term Applications
}

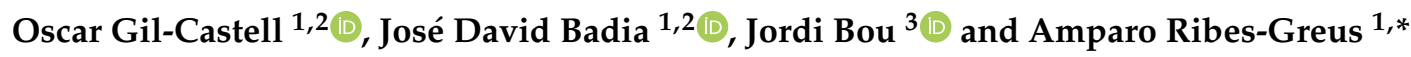 \\ 1 Instituto de Tecnología de Materiales (ITM), Universitat Politècnica de València, Camino de Vera s/n, \\ 46022 Valencia, Spain; ogilcastell@doctor.upv.es (O.G.-C.); jose.badia@uv.es (J.D.B.) \\ 2 Departament d'Enginyeria Química, Escola Tècnica Superior d'Enginyeria, Universitat de València, \\ Av. de la Universitat s/n, 46100 Burjassot, Spain \\ 3 Departament d'Enginyeria Química, Universitat Politècnica de Catalunya, Av. Diagonal 647 (ETSEIB), \\ 08028 Barcelona, Spain; Jordi.bou@upc.edu \\ * Correspondence: aribes@ter.upv.es
}

Received: 30 April 2019; Accepted: 20 May 2019; Published: 22 May 2019

\begin{abstract}
The evaluation of the performance of polyesters under in vitro physiologic conditions is essential to design scaffolds with an adequate lifespan for a given application. In this line, the degradation-durability patterns of poly(lactide-co-glycolide) (PLGA), polydioxanone (PDO), polycaprolactone (PCL) and polyhydroxybutyrate (PHB) scaffolds were monitored and compared giving, as a result, a basis for the specific design of scaffolds from short-term to long-term applications. For this purpose, they were immersed in ultra-pure water and phosphate buffer solution (PBS) at $37^{\circ} \mathrm{C}$. The scaffolds for short-time applications were PLGA and PDO, in which the molar mass diminished down to $20 \%$ in a 20-30 days lifespan. While PDO developed crystallinity that prevented the geometry of the fibres, those of PLGA coalesced and collapsed. The scaffolds for long-term applications were PCL and PHB, in which the molar mass followed a progressive decrease, reaching values of $10 \%$ for PCL and almost $50 \%$ for PHB after 650 days of immersion. This resistant pattern was mainly ascribed to the stability of the crystalline domains of the fibres, in which the diameters remained almost unaffected. From the perspective of an adequate balance between the durability and degradation, this study may serve technologists as a reference point to design polyester-based scaffolds for biomedical applications.
\end{abstract}

Keywords: biopolymer; polyester; PLGA; PCL; PDO; PHB; scaffolds; tissue engineering; in vitro hydrolytic degradation

\section{Introduction}

The polyesters are some of the most used polymeric materials for biomedical applications such as sutures, implants, artificial skin and controlled drug release [1-5]. Such is the case of the use of polylactide (PLA), polyglycolide (PGA), polycaprolactone (PCL), poly(lactide-co-glycolide) (PLGA), polydioxanone (PDO) or polyhydroxybutyrate (PHB). These polymeric materials degrade by hydrolytic processes and result in low molar mass species, that can be bioabsorbed and metabolised by the human body.

The irruption of electrospinning in tissue engineering has boosted the technology of production of biomaterials based on architectures of fibres, in which diameters can vary from the micrometric scale to hundreds of nanometres [6-8], mimicking the native extracellular matrix and allowing enough porosity to facilitate cellular growth [9]. Precisely, these scaffolds are required to ensure an appropriate balance between enough time of structural endurance to permit angiogenesis, and suitable degradation 
profiles to be decomposed avoiding an inflammatory response and eluding the delivery of toxic low molar mass compounds. These degradation by-products may affect healthy cells as well as interact with sensitive substances such as proteins and peptides or drugs [10].

Monitoring and understanding the physico-chemical processes underwent by biopolymeric scaffolds along their exposure to physiological conditions is essential to ensure their performance during application. In this sense, the study of their degradation profiles is necessary to guarantee the desired behaviour, according to the biomedical purpose, such as skin reparation [11,12] or cardiac surgeries [13-15], among others, which will need different times of endurance [16]. For instance, dissimilar regeneration periods may be considered according to the renewal rate on different tissues of the human body: 2-9 days for stomach cells, 10-30 days for skin epidermis cells, 30-60 days for trachea cells or 180 days for bone osteoblasts [17].

In the balance of the performance-to-degradation ratio of the scaffolds, the polymer composition plays an important role. Polymers from different origins and physico-chemical features have been proposed for tissue engineering [17]. Among them, natural polymers produced by microbes such as the polyhydroxybutyrate (PHB), as well as synthetic polymers such as the poly(lactide-co-glycolide) (PLGA), the polycaprolactone (PCL) or the polydioxanone (PDO) have been widely used for scaffold development. All of them are known to be resorbable, absorbable or bioabsorbable when implanted in the living body. However, their differences in the crystalline morphology may determine its hydrolytic degradation behaviour.

In vitro experiments are relevant to test and compare the performance of biopolymeric materials and assess their durability $[18,19]$. When the aqueous solution penetrates into the polymer, it swells incrementing the dimensions of the interface of contact, which promotes further degradation. The mechanism of degradation of polyesters under abiotic aqueous environments takes place through hydrolysis of the ester bonds, auto-catalysed by carboxylic groups, exponentially increasing along the exposure time [20]. These microstructural changes induce the formation of macroscopic pores or cracks, the loss of monomeric and oligomeric species, thus reducing the mass of the polymers and finally decomposing their architecture until bioassimilation or excretion [21]. Accordingly, after a successful growing and spreading of the cells into the scaffold, polyester-based scaffolds are expected to degrade, disintegrate and be assimilated by the patient.

Characterisation studies of the in vitro degradation of the most used polyesters for biomedical applications in bulk have been reported, with respect to its water-uptake rate, degradation kinetics and mechanisms, morphology and physico-chemical properties [22]. As electrospun scaffolds, some characterisation studies of in vitro degradation generally consider the monitoring of mass-loss and molar-mass along with hydrolytic exposure. The in vitro behaviour under physiological conditions for PLGA [14,23,24], PDO [25], PCL [26] and PHB [27] scaffolds has been individually assessed. These studies are usually carried out in the first stages of immersion and complete degradation or disintegration is not commonly addressed. Therefore, a comparison of the disintegration behaviour of these polymers under identic simulated conditions may offer a broader vision of their applicability, having in mind the expected lifetime for the future specific application [10].

The aim of this study was, therefore, to compare the in vitro degradation behaviour of PLGA, PCL, PDO and PHB scaffolds from an experimental and comprehensive perspective, under simulated physiologic conditions until complete disintegration. For this purpose, electrospun scaffolds were subjected to ultra-pure water and phosphate buffer solution (PBS) at $37^{\circ} \mathrm{C}$. Accordingly, a set of analytical techniques such as $\mathrm{pH}$ measurement, gravimetry, size-exclusion chromatography (SEC), differential scanning calorimetry (DSC) and field-emission scanning electron microscopy (FE-SEM) was proposed to point out the appropriate indicators to monitor and compare the in vitro hydrolytic degradation profiles of these polyester-based scaffolds for biomedical purposes. 


\section{Materials and Methods}

\subsection{Materials}

PLGA and PDO were provided by Sigma-Aldrich (Madrid, Spain) under the grades Resomer RG 505 and Resomer X, respectively; PCL was provided by Perstorp (Malmö, Sweden) under the grade CAPA 6800; PHB grade P209 was provided by Biomer (Krailling, Deutschland). Dimethylformamide (DMF), chloroform and hexafluoroisopropanol (HFIP) were used as solvents for electrospinning. For the hydrolytic degradation, ultra-pure water of type 1 (ISO 3696) [28] and Dulbecco's phosphate buffered saline solution (PBS, D1408) and $\mathrm{NaOH} 1 \mathrm{M}$ for adjusting $\mathrm{pH}$ in PBS, were used. All these reagents, except water, were supplied by Sigma-Aldrich and were used without further purification.

\subsection{Scaffold Preparation}

The fibrous scaffolds were obtained by electrospinning by means of an Yflow Electrospinner 2.2.D-350 (Málaga, Spain). It consisted of double polarization, integrated drum collector, control panel and robotized stage to move the electrospinning source in an alternative fashion covering a $400 \times$ $400 \mathrm{~mm}^{2}$ area. The solutions were prepared at different conditions, as described in Table 1 . The solution jet emerging from the stainless steel wire used as the positive electrode $(0.9 \mathrm{~mm}$ inner diameter $)$ was collected on a waxed paper. Scaffolds were dried over $12 \mathrm{~h}$ under vacuum to facilitate the removal of residual organic solvents and moisture and were stored for further analyses.

Table 1. Electrospinning conditions of the poly(lactide-co-glycolide) (PLGA), polydioxanone (PDO), polycaprolactone (PCL) and polyhydroxybutyrate (PHB) scaffolds.

\begin{tabular}{|c|c|c|c|c|c|}
\hline $\begin{array}{l}\text { Polymer } \\
\text { (type) }\end{array}$ & $\begin{array}{c}\text { Concentration } \\
(\% \mathrm{wt})\end{array}$ & Solvent (type) & $\begin{array}{l}\text { Feed Rate } \\
\left(\mathrm{mL} \cdot \mathrm{h}^{-1}\right)\end{array}$ & $\begin{array}{c}\text { Voltage } \\
(\mathbf{k V})\end{array}$ & $\begin{array}{c}\text { Distance } \\
\text { (cm) }\end{array}$ \\
\hline PCL & 18 & $\mathrm{DMF} / \mathrm{CHCl}_{3} 1: 8$ & 4 & $7.32 /-5.54$ & 25 \\
\hline PDO & 8 & HFIP & 1 & $3.85 /-3.35$ & 21 \\
\hline PHB & 23 & $\mathrm{CHCl}_{3}$ & 1 & $7.80 /-1.93$ & 20 \\
\hline PLGA & 30 & DMF & 1 & $9.15 /-8.80$ & 20 \\
\hline
\end{tabular}

\subsection{In Vitro Degradation Methodology}

All the electrospun scaffolds were subjected to hydrolytic degradation, by exposition to ultra-pure water and phosphate buffer saline solution (PBS), according to the international norm ISO 10993-13:2010, method 4.3 [29]. Shortly, the initial electrospun scaffolds were cut into rectangular specimens with a mass around $10 \mathrm{mg}$. The specimens were weighed $\left(m_{0}\right)$ and placed in a previously weighed vial $\left(m_{\text {vial }}\right)$. Ten millilitre of degradation medium were introduced and then the vials were sealed with polytetrafluoroethylene (PTFE) threaded plugs and placed in a thermostatically controlled oven at $37^{\circ} \mathrm{C}$. The $\mathrm{pH}$ of the PBS solution was adjusted to 7.4 with $\mathrm{NaOH} 1 \mathrm{M}$. Between twelve and fifteen extractions were considered along the hydrolytic degradation for each scaffold up to disintegration. Due to the different disintegration timespan of the studied scaffolds, two different time scales were considered, designated as short-term and long-term behaviour.

In order to monitor the process, after certain periods, the scaffolds were withdrawn from the environment by triplicates. The solid and liquid fractions were separated. The specimens coming from the saline buffer were washed with deionised water and then, along with those from water environment, were dried under vacuum to constant mass into the vials $\left(m_{d r y}\right)$ and saved for further analyses. The residual mass of the samples (\% mass) was determined by Equation (1),

$$
\% \text { mass }=\frac{m_{d r y}-m_{\text {vial }}}{m_{0}} \times 100
$$


where $m_{0}, m_{\text {vial }}$ are the initial mass of the specimen and the vial, respectively, and $m_{d r y}$ is the mass of the vacuum dry assembly sample-vial after degradation.

The $\mathrm{pH}$ of the degradation media was measured at room temperature by means of a Crison $\mathrm{pH} 25$ device. Three buffer solutions from Crison were used to calibrate $\mathrm{pH}$-meter: $\mathrm{pH} 4.01$ (phthalate buffer solution), pH 7.00 (phosphate buffer solution), $\mathrm{pH} 10.01$ (borate buffer solution).

\subsection{Scaffold Characterisation}

\subsubsection{Size Exclusion Chromatography (SEC)}

Size exclusion chromatography (SEC) analyses were carried out by means of an Agilent Infinity 1260 chromatograph (Basel, Switzerland). Separation was performed with a Jordi Associates mixed bed fluorinated column (permeation range: $100-10 \times 10^{6}$ Dalton). All samples were dissolved in mobile phase containing $2.72 \mathrm{~g} \cdot \mathrm{L}^{-1}$ of sodium trifluoroacetate (NaTFA). This solvent was previously degassed by vacuum filtration over PTFE $0.45 \mu \mathrm{m}$ pore membranes. The flow rate was set at $1 \mathrm{~mL} \cdot \mathrm{min}^{-1}$. One hundred microlitre samples of about $0.1 \%$ concentration were injected. Detection was conducted by UV-vis-detector. Monodisperse PMMA samples from Sigma Aldrich and Agilent were used for the previous calibration.

\subsubsection{Differential Scanning Calorimetry (DSC)}

The calorimetric data were obtained by means of a Mettler-Toledo DSC $820^{\mathrm{e}}$ differential scanning calorimeter (Columbus, OH, USA), previously calibrated following the procedure of In and $\mathrm{Zn}$ standards. The samples, with a mass of about $4 \mathrm{mg}$ were analysed between 0 and $200{ }^{\circ} \mathrm{C}$ with a heating/cooling/heating rate of $10{ }^{\circ} \mathrm{C} \cdot \mathrm{min}^{-1}$. All the experiments were run under a nitrogen atmosphere with a flow rate of $50 \mathrm{~mL} \cdot \mathrm{min}^{-1}$. The specimens were characterised at least in triplicate and the averages of temperatures and enthalpies were taken as representative values. The crystallinity degree $\left(X_{c}\right)$ was evaluated from the melting enthalpy results, by means of Equation (2),

$$
X_{c}(\%)=\frac{h_{m}}{h_{m}^{0}} \times 100
$$

where $\Delta h_{m}$ is the melting enthalpy of the sample and $\Delta h_{m}^{0}$ is the melting enthalpy of a perfect crystal of the given polymer (PDO $141 \mathrm{~J} \cdot \mathrm{g}^{-1}$ [30], PCL $148 \mathrm{~J} \cdot \mathrm{g}^{-1}$ [31] and PHB $146 \mathrm{~J} \cdot \mathrm{g}^{-1}$ [32]).

\subsubsection{Field Emission Scanning Electron Microscopy (FE-SEM)}

The surface morphology of the scaffolds was analysed by means of a Zeiss Ultra 55 field emission scanning electron microscope (Oberkochen, Germany). The samples were cut into small pieces and dried at $30{ }^{\circ} \mathrm{C}$ in a vacuum oven for $24 \mathrm{~h}$ and then kept in a desiccator during $48 \mathrm{~h}$. Afterwards, the specimens were mounted on metal studs and sputter-coated with a platinum layer during $10 \mathrm{~s}$ using a Leica EM MED020. The testing was performed at room temperature with a $2 \mathrm{kV}$ voltage. The fibre diameters were measured from the FE-SEM micrographs at random locations $(n=100)$ with the aid of the ImageJ software (National Institutes of Health, Bethesda, MD, USA).

\section{Results}

\subsection{Initial Properties and Morphology of the Scaffolds}

The in vitro degradation behaviour is mainly controlled by the polymer chemistry and physical features of the scaffold. Accordingly, some of the most influent parameters of a scaffold that will determine its subsequent biomedical application were assessed [33-35]. The initial surface morphology, fibre diameter, bulk density $(\rho)$ and surface density $\left(\rho_{\mathrm{s}}\right)$, along with the constitutional repeating unit (CRU) are gathered in Table 2. 
Table 2. Initial properties of the PLGA, PDO, PCL and PHB scaffolds.

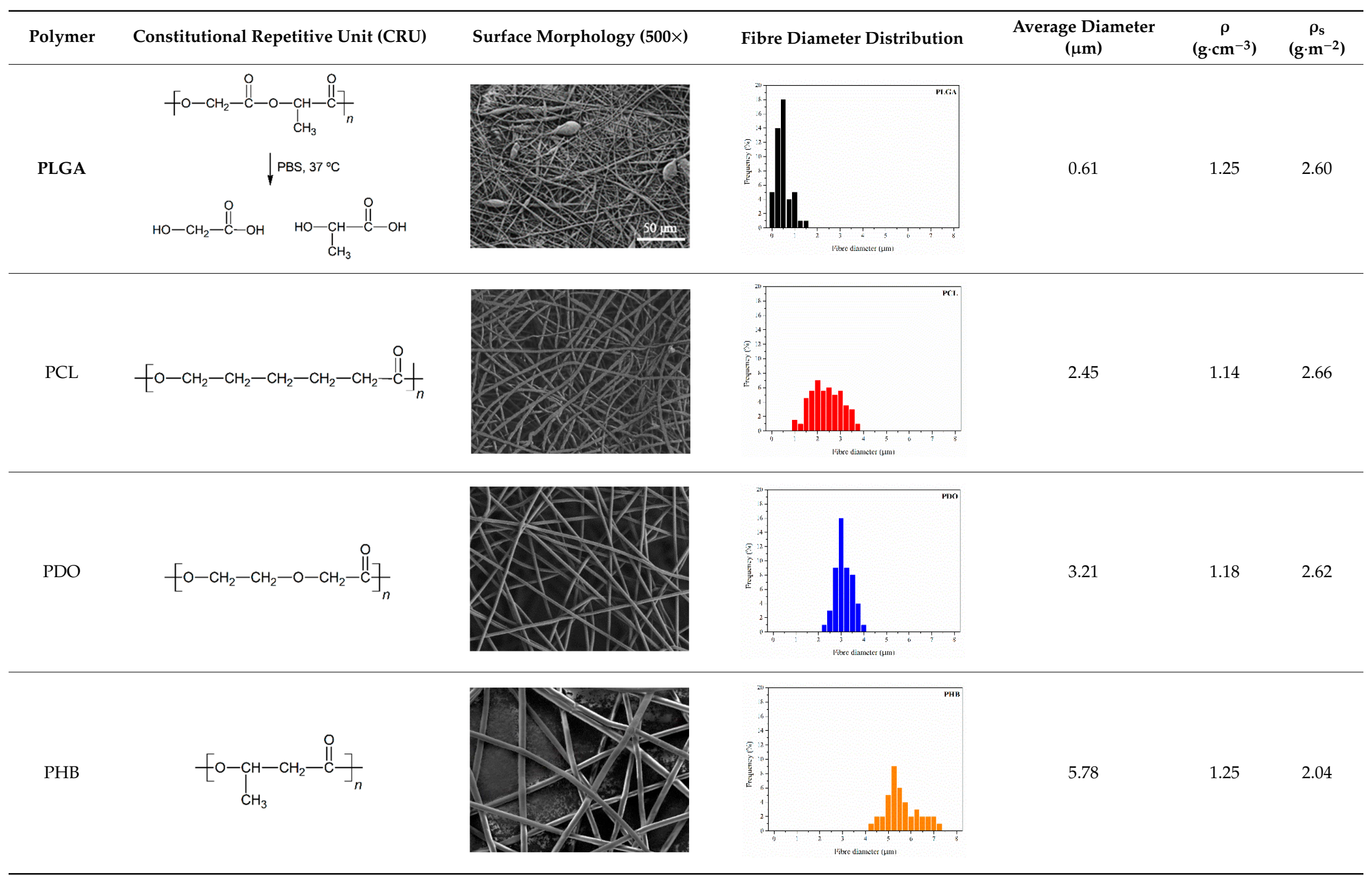


As the surface morphology revealed, all the scaffolds showed a uniform non-woven fibrous structure. Fibre diameters moved from the nanometric scale for the PLGA to the low micrometric scale of PCL, PDO and PHB. In addition, the diameter distributions of the PLGA and the PDO showed a narrow pattern, while those of the PCL and PHB tended to be wider. Similar bulk and surface densities were observed for all the scaffolds.

\subsection{Hydrolytic in Vitro Degradation}

\subsubsection{On-line Monitoring: Changes in the Media}

In order to preliminary assess the hydrolytic degradation of the scaffolds, the evolution of $\mathrm{pH}$ was monitored both when immersed in water and PBS. Due to the dissimilar degradation timespan of the studied scaffolds, the results were represented in two different time scales-short-term and long-term degradation-as plotted in Figure 1. According to the experimental design, the generated acidic compounds were measured as accumulation as a function of time. It must be taken into account that the evaluation of the degradation in water may bring information about the hydrolytic mechanism, while the consideration of PBS would better simulate the physiologic conditions.

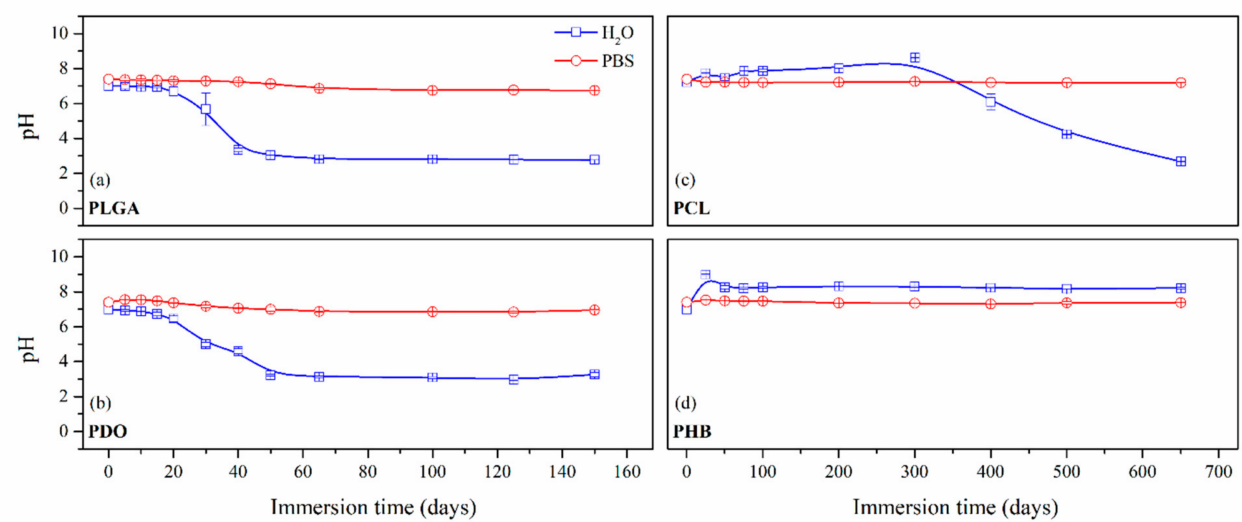

Figure 1. Average $\mathrm{pH}$ as a function of the degradation time in ultra-pure water and PBS for PLGA (a), PDO (b), PCL (c) and PHB (d) scaffolds.

Concerning the short-term scaffolds, the $\mathrm{pH}$ of the PLGA and PDO solutions remained constant during the first stage of immersion. When immersed in water, it dramatically decreased from neutral to acid $\mathrm{pH}$. This drop could be related to a large release of low molar mass acidic monomeric and oligomeric species such as glycolic acid, lactic acid for PLGA and low molar mass hydroxy-acid species for PDO [10,36]. As expected, when immersed into PBS, the pH slightly varied along the immersion due to the intrinsic ability to buffer acidic species released during degradation. Nonetheless, a slight diminution was observed from neutral $\mathrm{pH} 7.4$ to $\mathrm{pH}$ 6.6.

About the long-term scaffolds, two different behaviours were found. For PCL scaffolds immersed in water, the $\mathrm{pH}$ remained constant along the immersion until day 400, when it started to decrease due to the hypothetic release of acidic species based on hexanoic acid. Indeed, a progressive reduction was observed until the end of the assay, when $\mathrm{pH}$ value of 2.7 was found. Conversely, when immersed into PBS, the $\mathrm{pH}$ was maintained along the whole assay around 7.4 [37,38]. The hydrolytic degradation of the PHB scaffolds could not be perceived from the evaluation of the $\mathrm{pH}$ of the solution media. The $\mathrm{pH}$ remained constant in both water and PBS. Although the degradation of the PHB polymer chains ultimately results in 3-hydroxybutyric acid, which can be assimilated by the human organism [39], the slow degradation rate of this material seemed to have prevented the production of acidic low molar mass compounds that would have modified the $\mathrm{pH}$ of the media [40]. 


\subsubsection{Impact on the Scaffolds Mass and Molar Mass}

As perceived in the previous section, due to the different degradation performance of the studied scaffolds, the mass evolution along immersion was represented in short-term-PLGA and PDO-and long-term-PCL and PHB—scales, as shown in Figure 2.

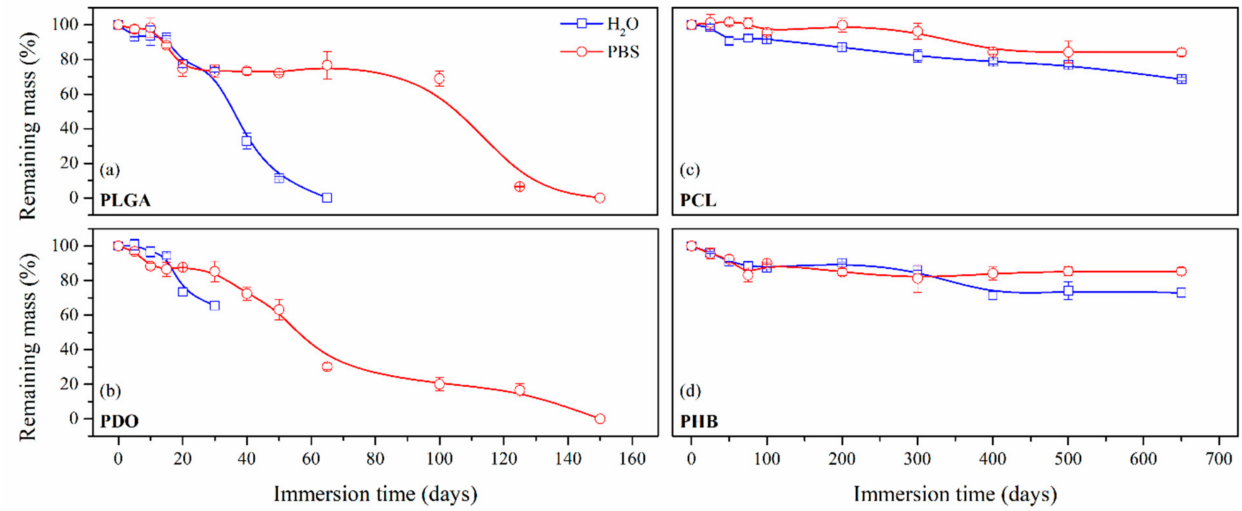

Figure 2. Remaining mass as a function of the degradation time in ultra-pure water and PBS for PLGA (a), PDO (b), PCL (c) and PHB (d) scaffolds.

On the one hand, the PLGA and PDO scaffolds were completely disintegrated in a relatively short period until day 150. In contrast, the degradation of the PCL and PHB was much slower and took place over a longer period. Even though the scaffolds were not completely dissolved, the monitoring of the degradation was studied until disintegration, which took place around day 650 of immersion both for PCL and PHB scaffolds. After this period, the remnant scaffolds were impossible to handle and the assay was considered as concluded.

The degradation behaviour was deeply assessed by means of the variation of the molar mass, which was monitored along the immersion by means of size exclusion chromatography (SEC). The molar mass distributions for the PLGA, PDO, PCL and PHB scaffolds are plotted in Figure 3 as a function of the immersion time. Unimodal distributions were found for PLGA, PDO and PCL scaffolds, while PHB showed a complex multi-modal broad molar mass distribution. It is important to note that samples coming from the hydrolytic degradation with a mass lower than $20 \%$ of the initial value were so deteriorated that could not be handled and, subsequently, molar mass analyses were not performed.

In general, the molar mass distributions were displaced towards lower values as a function of the immersion time due to the hydrolytic degradation of the ester bonds. For PLGA and PCL scaffolds, the distributions increased in width along the degradation, turning into a more polydisperse polymer. Random ester bond breakage seemed to take place in all polymeric chains, producing a broader distribution of chain sizes. For the case of the PDO scaffolds, the molar mass distributions reduced their width, turning into a more concise and sharp curve, which can be correlated with a less polydisperse polymer. Some authors found experimental evidence that suggested a preferential degradation of higher molar mass PDO chains, such as tie molecules, that resulted in a more uniform distribution of shorter polymer segments [21,41-43]. The broad multi-modal distribution pattern found for PHB showed two main peaks, correlated to low molar mass and high molar mass populations. This behaviour can be associated with the synthetic route of the PHB, in which microorganisms may have produced dissimilar size polymer chains [44,45]. Due to hydrolytic degradation, the PHB scaffolds reduced the high molar mass peak and increased that of low molar mass polymer chains as a function of the immersion time. 

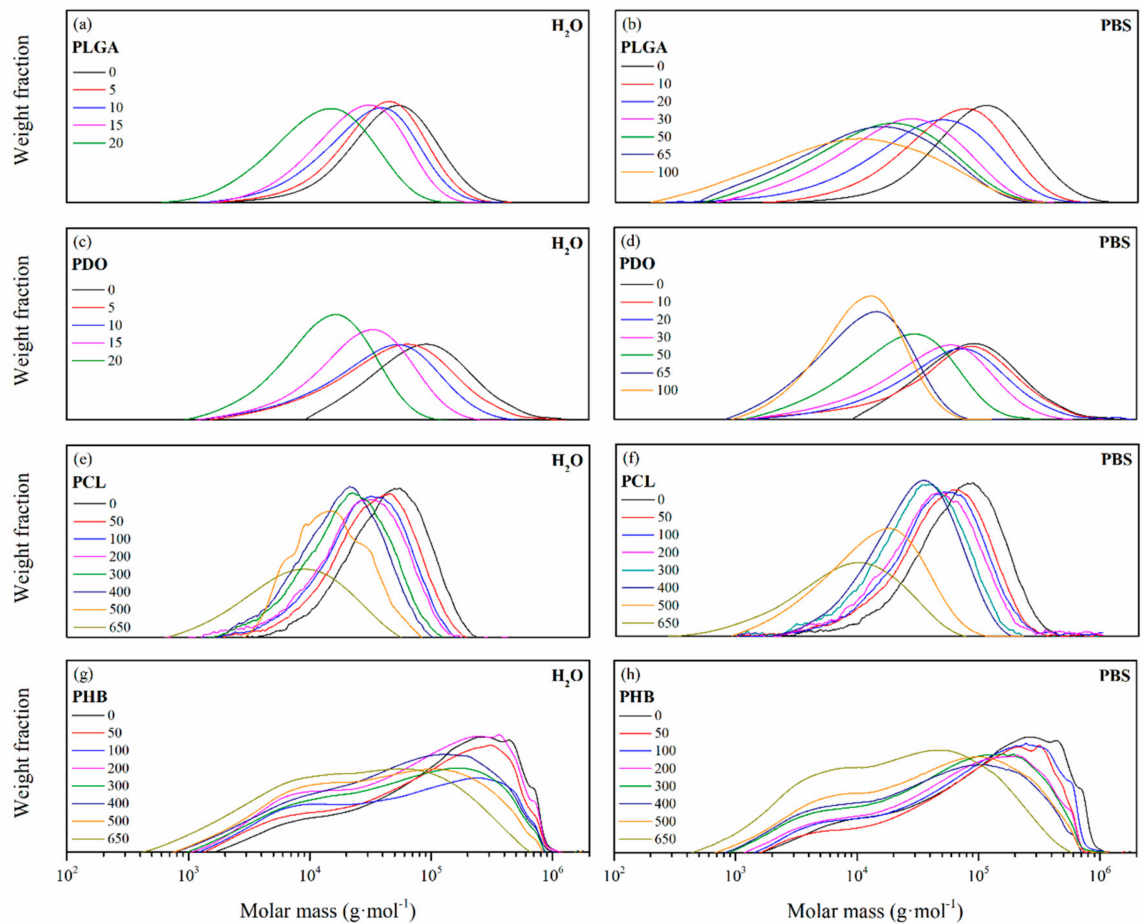

Figure 3. Molar mass distributions as a function of the degradation time in ultra-pure water and PBS for PLGA (a), (b), PDO (c), (d), PCL (e), (f), and PHB (g), (h) scaffolds.

The average molar mass in number $\left(M_{n}\right)$ was considered as an appropriate indicator for the comparison of the hydrolytic breakage of the polymer chains along the immersion, which values are gathered in Table 3. However, given the heterogeneity in the molar mass distributions for the different materials, the $M_{n}$ was normalised, i.e. relative molar mass-loss was calculated, and its evolution as a function of the immersion time was plotted in Figure 4 for a proper comparison.

Table 3. Average molar mass in number as a function of the degradation time in ultra-pure water and PBS for PLGA, PDO, PCL and PHB scaffolds.

\begin{tabular}{|c|c|c|c|c|c|c|c|c|c|}
\hline \multirow{3}{*}{$\begin{array}{l}\text { Immersion } \\
\text { time (Days) }\end{array}$} & & & & & \multirow{3}{*}{$\begin{array}{l}\text { Immersion } \\
\text { Time (Days) }\end{array}$} & \multicolumn{2}{|c|}{ PCL } & \multicolumn{2}{|c|}{ РНВ } \\
\hline & \multicolumn{4}{|c|}{$\operatorname{Mn}\left(\mathrm{g} \cdot \mathrm{mol}^{-1}\right)$} & & \multicolumn{4}{|c|}{$\mathrm{Mn}\left(\mathrm{g} \cdot \mathrm{mol}^{-1}\right)$} \\
\hline & $\mathrm{H}_{2} \mathrm{O}$ & PBS & $\mathrm{H}_{2} \mathrm{O}$ & PBS & & $\mathrm{H}_{2} \mathrm{O}$ & PBS & $\mathrm{H}_{2} \mathrm{O}$ & PBS \\
\hline 0 & \multicolumn{2}{|c|}{43,290} & \multicolumn{2}{|c|}{52,000} & 0 & \multicolumn{2}{|c|}{42,030} & \multicolumn{2}{|c|}{20,450} \\
\hline 5 & 36,080 & 38,210 & 30,800 & 50,450 & 50 & 36,080 & 34,500 & 18,490 & 19,510 \\
\hline 10 & 26,020 & 25,780 & 28,080 & 48,880 & 100 & 30,010 & 28,820 & 15,700 & 17,040 \\
\hline 20 & 12,690 & 15,850 & 16,620 & 30,260 & 200 & 27,810 & 25,390 & 14,900 & 14,850 \\
\hline 30 & - & 8340 & 13,030 & 21,990 & 300 & 18,470 & 19,670 & 14,250 & 13,610 \\
\hline 50 & - & 5960 & - & 14,460 & 400 & 8350 & 8380 & 13,650 & 12,350 \\
\hline 65 & - & 4800 & - & 12,710 & 500 & 7520 & 5370 & 12,960 & 12,520 \\
\hline 100 & - & 4360 & - & 9450 & 650 & 3340 & 3060 & 10,760 & 9440 \\
\hline
\end{tabular}

The decrease of the $M_{n}$ for the short-term PLGA and PDO scaffolds followed a similar exponential decreasing pattern regardless of the degradation medium, as observed by other authors [36,46,47]. Although the degradation of the PLGA scaffolds in water and PBS followed an identical pattern, for the case of PDO scaffolds a slightly delayed behaviour was found when immersed in PBS. If results are compared to mass loss measurements, one can see that after the $M_{n}$ reached values near to the $20 \%$ of 
the initial values, a plateau in the remaining mass was found prior to the complete disintegration of both PLGA and PDO scaffolds.
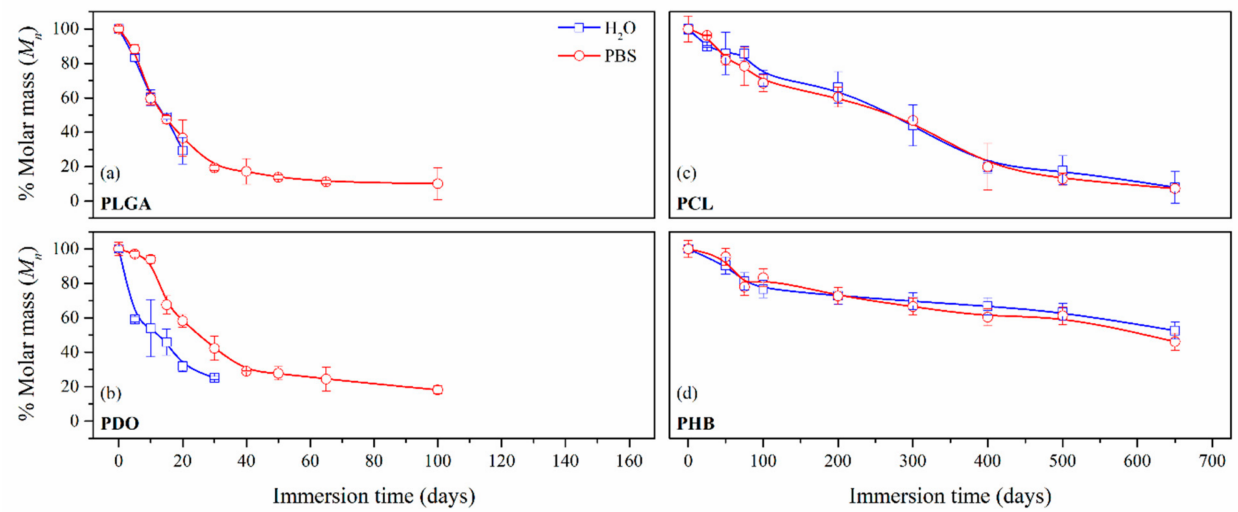

Figure 4. Average molar mass in number $\left(\mathrm{M}_{\mathrm{n}}\right)$ percentage as a function of the degradation time in ultra-pure water and PBS for PLGA (a), PDO (b), PCL (c) and PHB (d) scaffolds.

In contrast, long-term PCL and PHB scaffolds showed a similar progressive decrease of the $M_{n}$ as a function of time. Although the measurements of mass for PCL showed a reduction between $10 \%$ and $20 \%$ after 650 days of immersion, the molar mass results revealed a massive reduction of $M_{n}$ of around $80 \%$. However, in PHB scaffolds, the $M_{n}$ decreased 50\% during the 650 days of immersion in both water and PBS. These results might be explained in terms of crystallinity, which might block the diffusion of the hydrolytic media into the polymers and retard the degradation [48]. This hypothesis was confirmed, as latterly shown by the results of differential scanning calorimetry.

\subsubsection{Impact on the Scaffolds Crystallinity}

The study of the thermal properties is essential to understand the behaviour of polymers subjected to different degrading conditions [49-58]. The thermal properties of the scaffolds were assessed by means of differential scanning calorimetry (DSC). Figure 5 shows the calorimetric curves of the first heating scan of non-exposed scaffolds and those subjected to in vitro hydrothermal degradation in both media, ultra-pure water and PBS. In order to assure comparison between the different materials, the thermal properties were evaluated from 0 to $200{ }^{\circ} \mathrm{C}$.

PLGA showed an amorphous morphology, while PDO, PCL and PHB showed a semicrystalline behaviour, regardless of the time subjected to hydrolytic degradation. Due to the different morphology of the selected materials, the endothermic specific enthalpy related to the release of energy during the glass transition $\left(\Delta h_{r-g t}\right)$ was chosen for PLGA and the crystallinity degree $\left(X_{c}\right)$ for PDO, PCL and PHB scaffolds. The results are plotted in Figure 6. Moreover, Table 4 gathers the peak temperature of the heat release during the glass transition $\left(T_{r-g t}\right)$ for the PLGA and the peak melting temperature $\left(T_{m}\right)$ for the PDO, PCL and PHB scaffolds, closely related to the lamellar thickness $\left(l_{c}\right)[59,60]$.

For the case of the amorphous PLGA scaffolds, a similar but delayed behaviour was found for the endothermic peak associated with the glass transition during immersion in water and PBS. This transition sharpened at short degradation times but reduced its associated enthalpy $\left(\Delta h_{r-g t}\right)$. Then, it became broader the longer the hydrolytic exposure was until it almost disappeared. As can be seen in Figure 5, particularly when immersed in PBS, the unimodal performance turned into a bimodal transition pattern, which was ascribed to the glass transition of different segments of the copolymer, i.e., polyglycolide (PGA), between 35 and $40^{\circ} \mathrm{C}$, and polylactide (PLA), between 55 and $60{ }^{\circ} \mathrm{C}$ [61]. These results are in line with other reports that suggested a preferential hydrolytic breakage of the glycolic-glycolic and glycolic-lactic ester linkages, instead of that of the lactic-lactic bond in random poly(lactide-co-glycolide) [54]. 
In the same time-scale, PDO scaffolds showed complex semicrystalline behaviour. A coldcrystallisation exothermic peak was perceived immediately before the melting transition. According to Sabino et al., the cold-crystallisation around $80{ }^{\circ} \mathrm{C}$ can be ascribed to a partial melting and recrystallization of non-stable crystalline structure [43]. Then, a unimodal melting transition around $108^{\circ} \mathrm{C}$ was observed. When immersed in water, the cold-crystallisation remained constant and the melting enthalpy slightly increased, suggesting that crystallinity was developed during immersion [62]. The melting temperature $\left(T_{m}\right)$ slightly decreased, ascribed to a more imperfect crystalline structure with lower lamellar thickness. However, when immersed in PBS, the cold-crystallisation peak disappeared as a function of time and the melting peak turned into a bimodal pattern, suggesting the existence of dissimilar crystalline populations. Highly degraded PDO segments with lower entanglement capability, seemed to have rearranged into an imperfect crystalline structure that melted at lower temperatures, around $86^{\circ} \mathrm{C}$ [22]. The global crystallinity degree increased along the immersion from $35 \%$ up to $60 \%$.
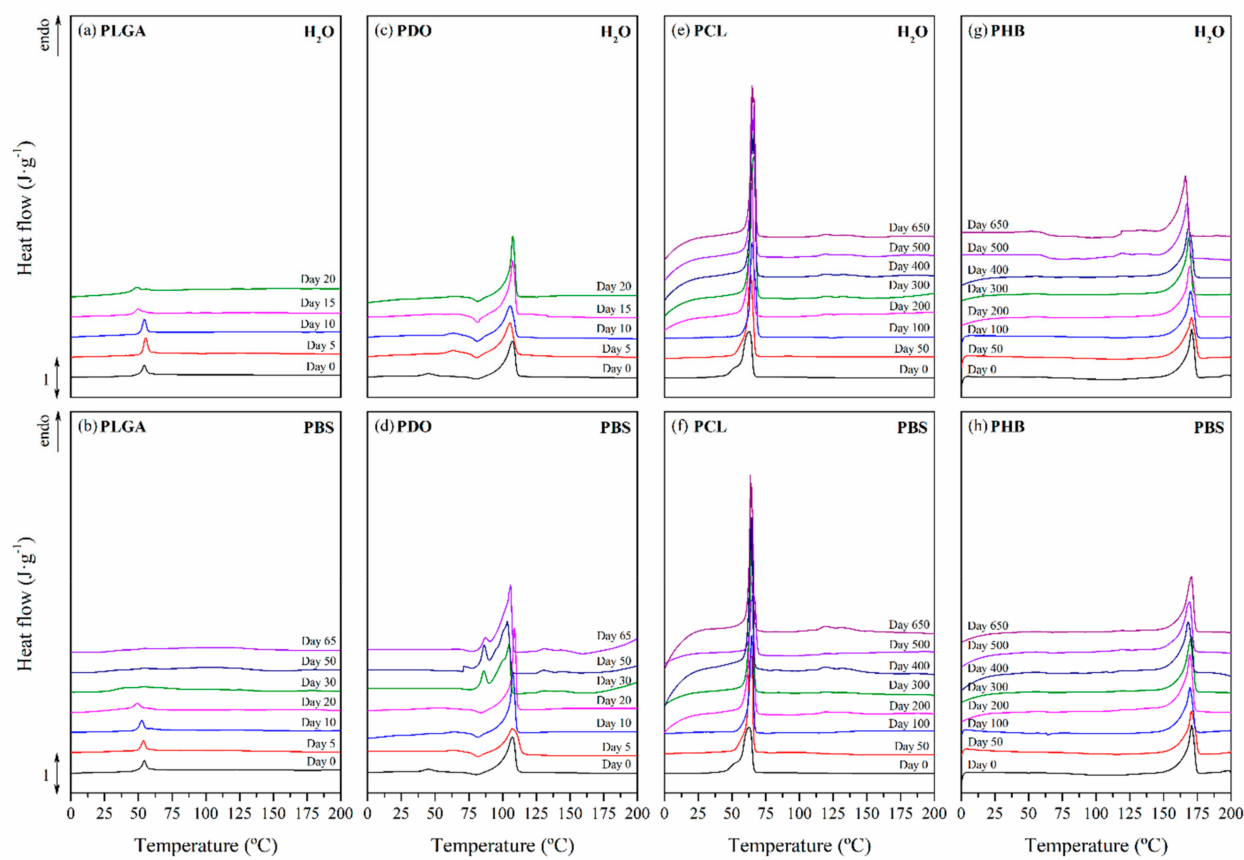

Figure 5. Differential scanning calorimetry traces as a function of immersion time in ultra-pure water and PBS for PLGA (a), (b), PDO (c), (d), PCL (e), (f), and PHB (g), (h) scaffolds.
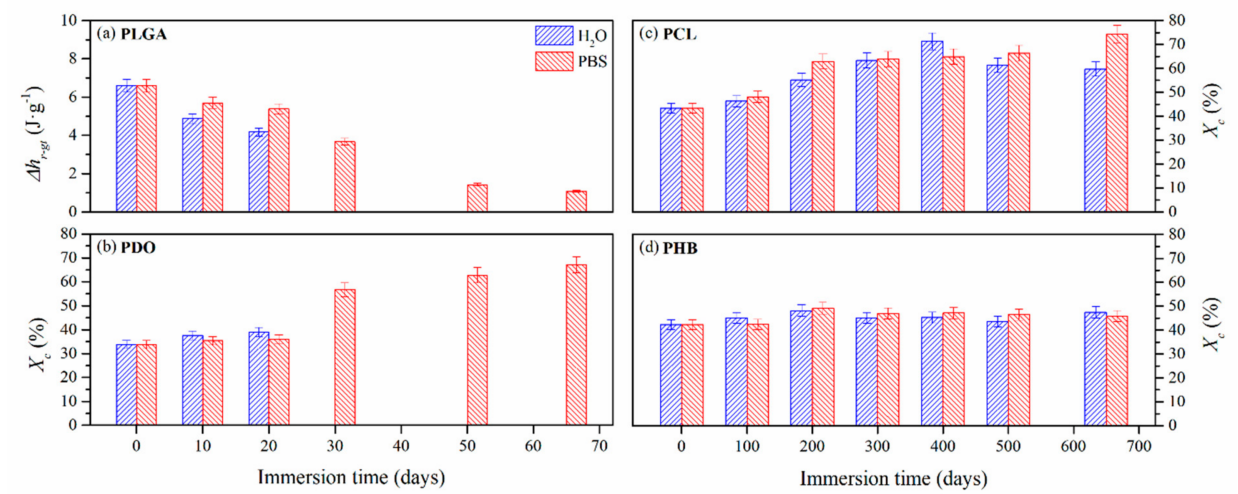

Figure 6. Evolution of the structural relaxation enthalpy $\left(\Delta \mathrm{h}_{\mathrm{r}-\mathrm{gt}}\right)$ for PLGA $(\mathbf{a})$ and crystallinity degree $\left(\mathrm{X}_{\mathrm{c}}\right)$ for PDO (b), PCL (c) and PHB (d) scaffolds as a function of immersion time in ultra-pure water and PBS. 
Table 4. Peak temperature of the heat release during the glass transition $\left(\mathrm{T}_{\mathrm{r}-\mathrm{gt}}\right)$ for the PLGA and the peak melting temperature (Tm) for the PDO, PCL and PHB scaffolds as a function of immersion time in ultra-pure water and PBS. Standard deviation between 0 and $1 \%$ was omitted for the sake of clarity.

\begin{tabular}{|c|c|c|c|c|c|c|c|c|c|}
\hline \multirow{3}{*}{$\begin{array}{l}\text { Immersion } \\
\text { Time (Days) }\end{array}$} & \multirow{2}{*}{\multicolumn{2}{|c|}{$\begin{array}{c}\text { PLGA } \\
\mathrm{T}_{\mathrm{r}-\mathrm{gt}}\left({ }^{\circ} \mathrm{C}\right) \\
\end{array}$}} & \multirow{2}{*}{\multicolumn{2}{|c|}{$\frac{\text { PDO }}{\mathrm{T}_{\mathrm{m}}\left({ }^{\circ} \mathrm{C}\right)}$}} & \multirow{3}{*}{$\begin{array}{l}\text { Immersion } \\
\text { Time (Days) }\end{array}$} & \multirow{2}{*}{\multicolumn{2}{|c|}{$\frac{\text { PCL }}{T_{m}\left({ }^{\circ} \mathrm{C}\right)}$}} & \multirow{2}{*}{\multicolumn{2}{|c|}{$\frac{\text { PHB }}{T_{m}\left({ }^{\circ} \mathrm{C}\right)}$}} \\
\hline & & & & & & & & & \\
\hline & $\mathrm{H}_{2} \mathrm{O}$ & PBS & $\mathrm{H}_{2} \mathrm{O}$ & PBS & & $\mathrm{H}_{2} \mathrm{O}$ & PBS & $\mathrm{H}_{2} \mathrm{O}$ & PBS \\
\hline 0 & \multicolumn{2}{|c|}{54.5} & \multicolumn{2}{|c|}{107.9} & 0 & \multicolumn{2}{|c|}{63.0} & \multicolumn{2}{|c|}{170.9} \\
\hline 5 & 55.3 & 53.6 & 105.4 & 107.7 & 50 & 63.8 & 64.4 & 170.6 & 170.8 \\
\hline 10 & 54.5 & 52.5 & 105.9 & 107.8 & 100 & 64.8 & 64.5 & 169.8 & 169.5 \\
\hline 20 & 48.6 & 49.3 & 105.2 & 108.4 & 200 & 64.8 & 64.5 & 169.4 & 169.4 \\
\hline 30 & - & 41.1 & - & 104.1 & 300 & 66.0 & 64.1 & 168.5 & 170.6 \\
\hline 50 & - & - & - & 103.5 & 400 & 65.4 & 64.2 & 168.3 & 168.3 \\
\hline 65 & - & - & - & 105.9 & 500 & 64.2 & 64.2 & 167.6 & 169.5 \\
\hline - & - & - & - & - & 650 & 63.8 & 64.4 & 166.3 & 169.2 \\
\hline
\end{tabular}

The PCL scaffolds showed a typical semi-crystalline behaviour with a melting transition around $63{ }^{\circ} \mathrm{C}$. No significant differences were perceived when immersed in water and PBS. In both media, the melting peak sharpened and increased the associated crystallinity degree, from $40 \%$ up to $70 \%$ after 650 days of immersion. Shorter hydrolysed molecular PCL segments rearranged and crystallised as a function of time [33]. Given the small increase in the melting temperature, slightly more perfect crystals with higher lamellar thickness were developed during immersion [63].

The evaluation of the thermal properties of the PHB scaffolds revealed a semicrystalline behaviour with a melting peak around $171{ }^{\circ} \mathrm{C}$, which was slightly displaced towards lower temperatures, correlated to more imperfect crystals as a function of the immersion time, due to the progress of the hydrolytic degradation. However, the crystallinity degree slightly increased from $42 \%$ to $47 \%$ after 650 days of immersion in both media [64]. These results suggested that the microstructure of the PHB scaffolds remained almost stable during the immersion period considered in this study.

The hydrolytic process of semicrystalline polyesters occurred in two stages: (i) the attack of the less compacted amorphous regions where diffusion of the hydrolytic medium is easier and faster and (ii) the attack on the crystalline regions, usually hydrophobic and impermeable to the diffusion and penetration of the aqueous media [33,34]. The crystalline fraction of the long-term scaffolds may have been relevant in terms of the increase in the difficulty of the hydrolytic media to penetrate, swell and scissor the polymeric chains. It was therefore in agreement with the resilience of the $M_{n}$ and mass of the PCL and PHB scaffolds.

\subsubsection{Impact on the Scaffolds Surface Morphology}

Finally, the change of the surface morphology of the scaffolds as a function of immersion time in ultra-pure water and PBS was monitored. The fibrous structure of the scaffold is required to remain for a certain period of time in order to allow cells to attach and proliferate [13]. The surface micrographs of PLGA and PDO are shown in Figure 7 while those of PCL and PHB scaffolds are shown in Figure 8. The average fibre diameters are gathered in Table 5.

Different behaviour was perceived in the fibrous morphology of the short-term degraded scaffolds. In the PLGA scaffolds, fibres swelled and coalesced along the immersion, as perceived in the fibre diameter increase [3]. As well, some microscopic pores appeared and grew in the surface of the fibres when immersed in water and, subsequently, the disintegration occurred around day 20 . When immersed into PBS, the fibres also swelled, but the degradation process seemed to be slower than in water. Although swelling took place, conglutination was not completely reached in the scaffolds after 65 days of immersion. For PDO scaffolds, a slight reduction of the fibre diameter was found along the 
immersion in both media. The fibres did not coalesce and collapsed, probably due to the presence of the crystalline fraction. The degradation of the scaffolds occurred through fibre breakage in a longer timespan than for PLGA. The fibrous structure remained apparently unaffected until disintegration, which happened around day 60 of immersion.

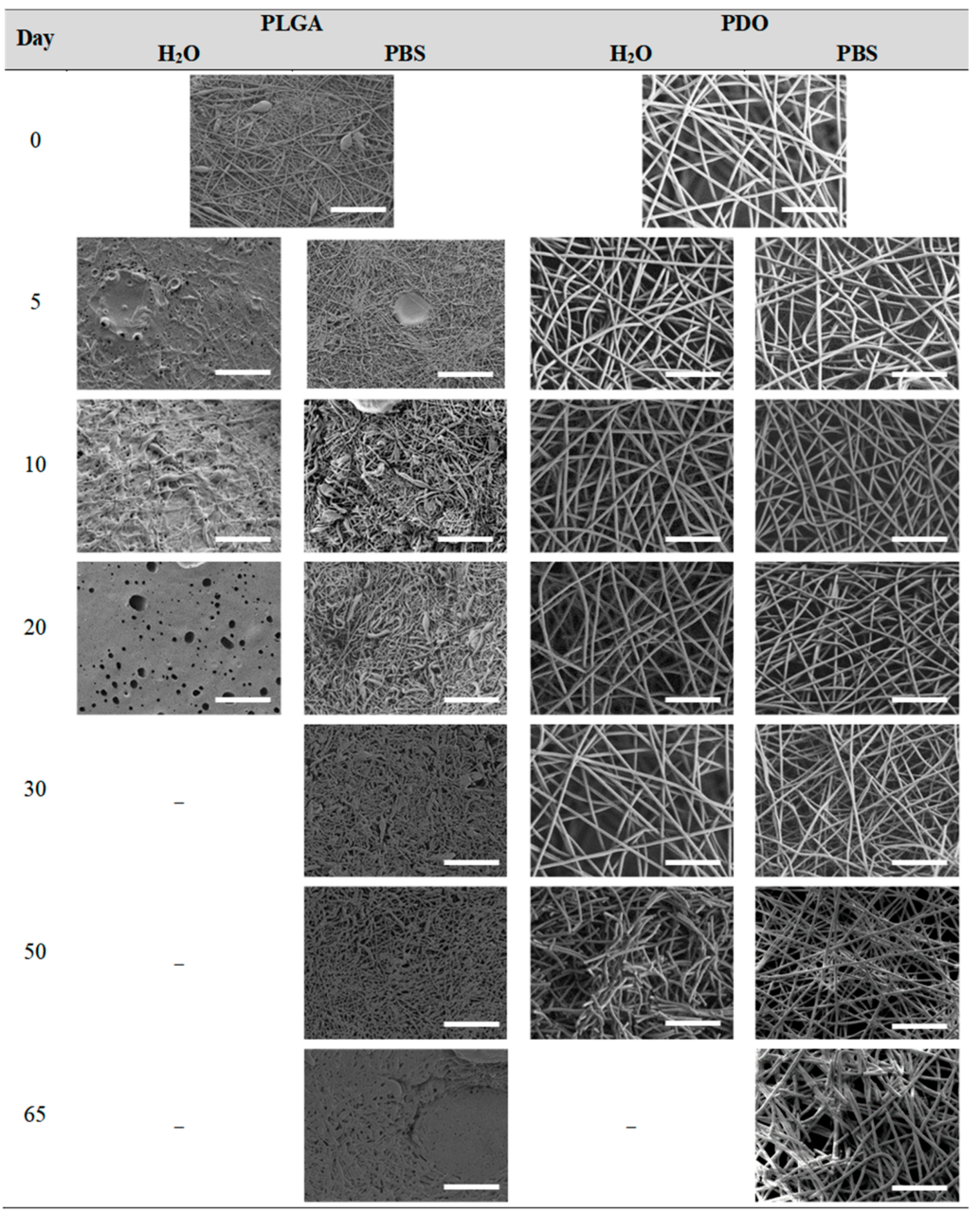

Figure 7. Surface morphology as a function of immersion time in ultra-pure water and PBS for PLGA and PDO scaffolds (500×: scale bar $50 \mu \mathrm{m})$.

Table 5. Average fibre diameter as a function of the degradation time in ultra-pure water and PBS for PLGA, PDO, PCL and PHB scaffolds.

\begin{tabular}{|c|c|c|c|c|c|c|c|c|c|}
\hline \multirow{3}{*}{$\begin{array}{l}\text { Immersion } \\
\text { Time (Days) }\end{array}$} & & & & & \multirow{3}{*}{$\begin{array}{l}\text { Immersion } \\
\text { Time (Days) }\end{array}$} & \multicolumn{2}{|c|}{ PCL } & \multicolumn{2}{|c|}{ PHB } \\
\hline & \multicolumn{4}{|c|}{ Diameter $(\mu \mathrm{m})$} & & \multicolumn{4}{|c|}{ Diameter $(\mu \mathrm{m})$} \\
\hline & $\mathrm{H}_{2} \mathrm{O}$ & PBS & $\mathrm{H}_{2} \mathrm{O}$ & PBS & & $\mathrm{H}_{2} \mathrm{O}$ & PBS & $\mathrm{H}_{2} \mathrm{O}$ & PBS \\
\hline 0 & \multicolumn{2}{|c|}{0.610} & \multicolumn{2}{|c|}{3.214} & 0 & \multicolumn{2}{|c|}{2.458} & \multicolumn{2}{|c|}{5.783} \\
\hline 5 & 2.842 & 1.925 & 3.197 & 3.214 & 50 & 2.634 & 2.238 & 5.409 & 5.120 \\
\hline 10 & 3.261 & 2.062 & 3.191 & 3.021 & 100 & 2.383 & 2.140 & 4.704 & 5.374 \\
\hline 20 & - & 1.869 & 2.988 & 2.921 & 200 & 2.309 & 2.294 & 4.802 & 5.055 \\
\hline 30 & - & 1.919 & 2.720 & 2.749 & 300 & 2.133 & 2.681 & 4.797 & 4.907 \\
\hline 50 & - & 1.905 & - & 2.432 & 400 & 2.644 & 2.187 & 4.918 & 4.942 \\
\hline \multirow[t]{2}{*}{65} & - & 3.823 & - & 2.090 & 500 & 2.262 & 2.121 & 4.817 & 5.004 \\
\hline & & & & & 650 & 2.150 & 2.455 & 4.755 & 4.861 \\
\hline
\end{tabular}




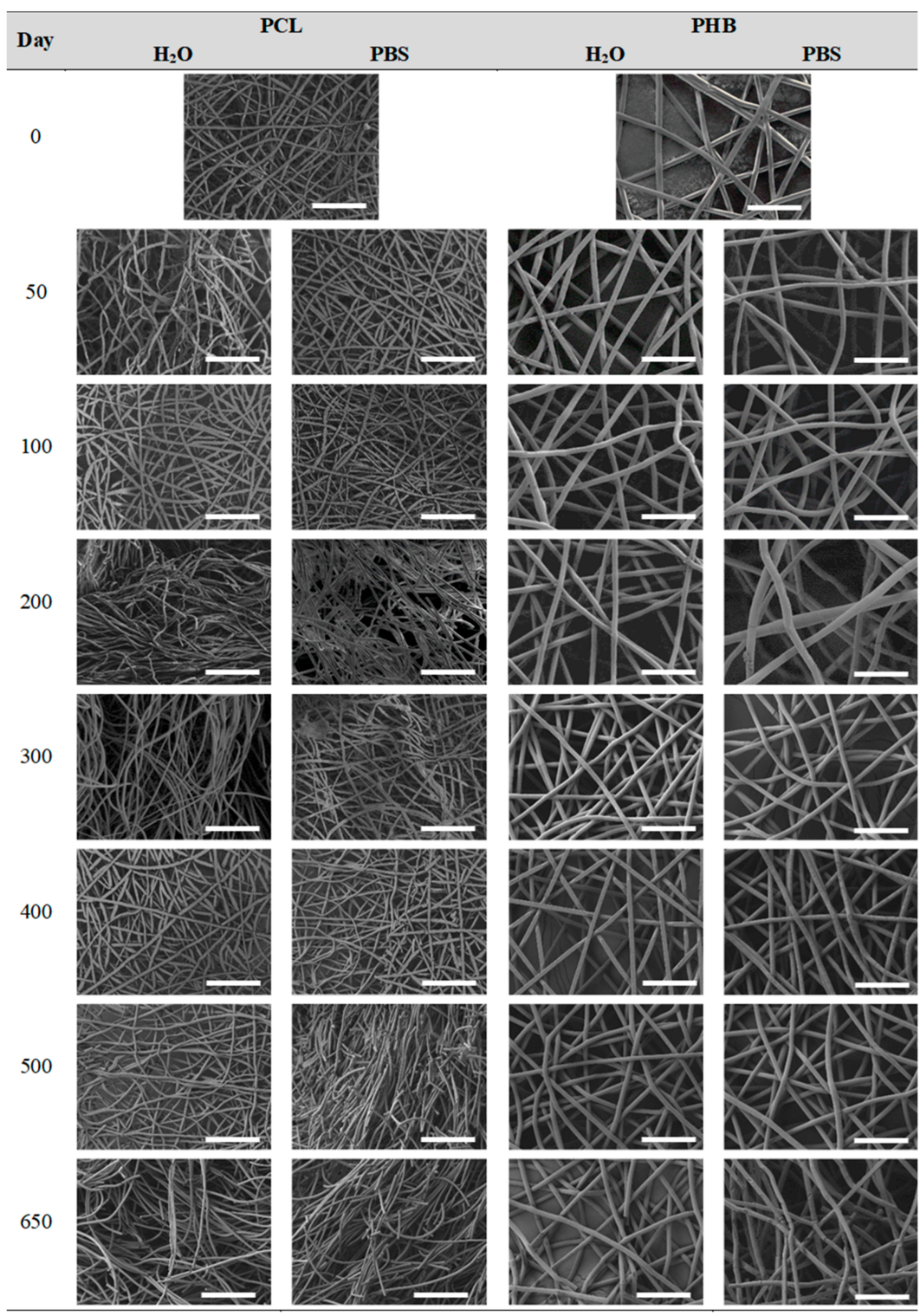

Figure 8. Surface morphology as a function of immersion time in ultra-pure water and PBS for PCL and PHB scaffolds (500x: scale bar $50 \mu \mathrm{m})$.

In contrast, the fibrous structure of the PCL and PHB scaffolds remained almost unaffected during immersion, as revealed by the average fibre diameter [26]. Fibre breakage was perceived from day 500 onwards in the PCL scaffolds. After 650 days, the scaffolds were almost disintegrated as shown by the high degree of fibre rupture. Remarkable fibre breakage in PHB scaffolds was also found at 650 days of immersion. These observations confirm the high stability under hydrolytic conditions of these polymers that permitted to preserve the fibres unaltered until the last stages of immersion.

\section{Discussion}

Given the polyester nature of the scaffolds, the feasible ester bond scission and the generation of shorter polymer segments with new carboxyl groups and acidification of the media during immersion may take place [10]. In this line, due to the different polymers analysed, the changes in the molar mass are expected to depend on the chemical structure, but also on the scaffold crystalline morphology. As well, the variation of the fibrous structure of the scaffolds may be correlated to the above-cited behaviour. For a proper comparison, the overview of the degradation features of the different analysed scaffolds is gathered in Table 6. 
Table 6. Overview of the hydrolytic degradation behaviour of PLGA, PDO, PCL and PHB when subjected to physiologic conditions (PBS, $\left.37^{\circ} \mathrm{C}\right)$.

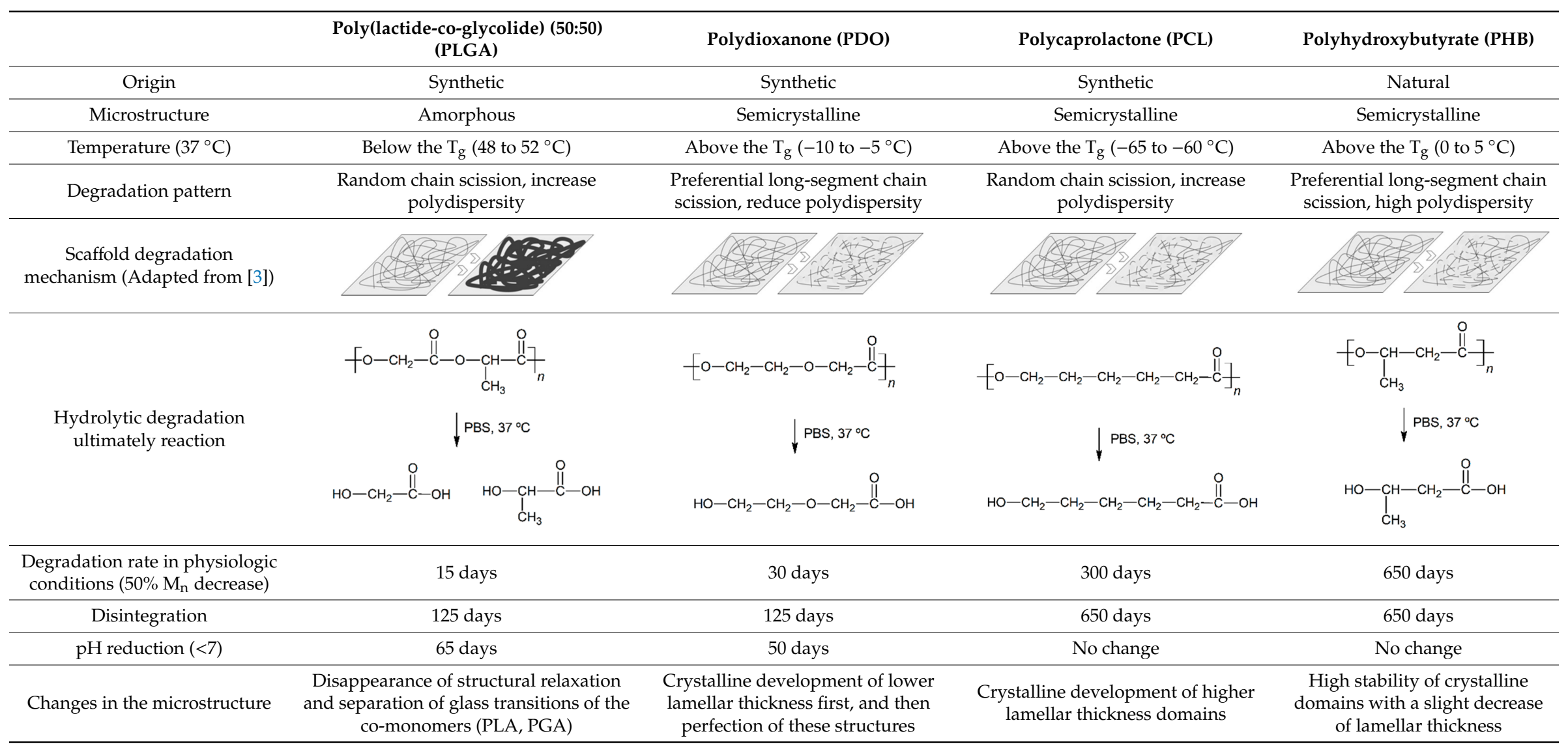


The PLGA fibres swelled as a function of the immersion time, reducing the inter-fibre distance and tending to close the pores required for satisfactory cell adhesion and proliferation. The mainly amorphous morphology of this polymer may have contributed to rapid diffusion of the aqueous solvent into the fibres. Meanwhile, the hydrolytic degradation of the polymer molecules occurred from the very beginning of immersion, following a random scission pattern, as suggested by the increase in the polydispersity index. Consequently, the molar mass dramatically decreased and low molar mass compounds were released from the scaffold, promoting acidification of the surrounding media. Finally, the scaffold collapsed and released glycolic and lactic acid monomers and oligomers that were completely dissolved in the hydrolytic media.

The PDO scaffolds kept the fibrous morphology along the degradation until disintegration. The fibre diameter slightly diminished during immersion and small cracks perpendicular to the axis of the fibres were perceived. The presence of the ether bond in the backbone may have promoted the more progressive degradation behaviour of this material. The typical cold-crystallisation of this polymer disappeared along the immersion and an imperfect crystalline population was developed, which induced higher resistance than PLGA to coalesce and collapse. Nonetheless, the fibre erosion and breakage resulted in the progressive molar mass loss, mass-loss and the reduction of the $\mathrm{pH}$ due to the release of low molar mass species, as produced from the preferential bond scission of the ester linkages.

The morphology of the PCL fibres remained mainly unaffected along the immersion. The average fibre diameter slightly varied and the fibrous morphology persisted until disintegration. Crystallinity was developed in this scaffold due to the increase of mobility of short hydrolysed segments, aided by the plasticizing effect of water along with the temperature above the glass transition. As a consequence of having more crystalline domains with higher lamellar thickness, PCL was more capable of preventing the structure of its fibres from degradation. The molar mass followed an almost linear diminishing trend until complete disintegration. The polydispersity increased, suggesting a random chain scission phenomenon that resulted in dissimilar segment sizes during degradation.

The hydrolytic behaviour of the PHB fibres revealed that the mass, the $\mathrm{pH}$, the fibre diameter and the fibrous morphology remained constant until disintegration. Moreover, the crystallinity degree did not significantly varied during immersion. The highly stable crystalline structure of the PHB stimulated a slight and progressive chain scission process along the immersion, as suggested by the evolution of the molar mass distributions. The broad multi-modal behaviour of PHB remained almost unchanged as a function of the immersion time. However, the peak correlated to high molar mass segments decreased, while that of low molar mass polymer chains increased. This behaviour suggested preferential degradation of high molar mass domains. Overall, the PHB scaffolds were found to be the most stable of the evaluated materials, which revealed the slowest degradation behaviour when subjected to physiologic conditions.

\section{Conclusions}

The hydrolytic degradation patterns of scaffolds based on polyesters such as poly(lactide-co-glycolide) (PLGA), polydioxanone (PDO), polycaprolactone (PCL), and polyhydroxybutyrate (PHB) were monitored under in vitro simulated physiologic conditions. The PLGA and PDO scaffolds exhibited a short-term degradation performance, while those of PCL and PHB revealed a long-term and progressive degradation profile. Further evaluation of the behaviour of the scaffolds during immersion revealed that they possess different mechanisms of degradation, in which the decrease of the molar mass is strictly correlated to the polymer composition, but also to the scaffold crystalline structure, which will determine its subsequent biomedical application.

The results of this study may serve as a reference point in the design and selection of polyester-based electrospun scaffolds for biomedical applications, from the perspective of an adequate balance between the durability and degradation pattern under physiologic conditions.

Author Contributions: Conceptualization, O.G.-C., J.D.B. and A.R.-G.; Formal analysis, O.G.-C., J.D.B., J.B. and A.R.-G.; Funding acquisition, A.R.-G.; Investigation, O.G.-C.; Methodology, O.G.-C., J.D.B. and J.B.; Project 
administration, A.R.-G.; Resources, O.G.-C.; Software, O.G.-C.; Supervision, J.D.B. and A.R.-G.; Validation, O.G.-C. and J.D.B.; Visualization, J.D.B. and A.R.-G.; Writing—original draft, O.G.C.; Writing-review and editing, J.D.B., J.B. and A.R.G.

Funding: This research was funded by MINISTERIO DE ECONOMÍA, INDUSTRIA Y COMPETITIVIDAD, grant number ENE2017-86711-C3-1-R and by the MINISTERIO DE EDUCACIÓN, CULTURA Y DEPORTE, grant number FPU13/01916.

Acknowledgments: AITEX Textile Research Institute is thanked for the scaffold supplying in the context of the MASCONFORT and IMINTEX projects, financed by Generalitat Valenciana.

Conflicts of Interest: The authors declare no conflict of interest. The funders had no role in the design of the study; in the collection, analyses, or interpretation of data; in the writing of the manuscript, or in the decision to publish the results.

\section{References}

1. Ulery, B.D.; Nair, L.S.; Laurencin, C.T. Biomedical applications of biodegradable polymers. J. Polym. Sci. Part B Polym. Phys. 2011, 49, 832-864. [CrossRef] [PubMed]

2. Ratner, B.D.; Hoffman, A.S.; Schoen, F.J.; Lemons, J.E. Biomaterials Science: An Introduction to Materials in Medicine; Academic Press, Elsevier: Cambridge, MA, USA, 2013; ISBN 9780123746269.

3. Li, W.-J.; Cooper, J.A.; Mauck, R.L.; Tuan, R.S. Fabrication and characterization of six electrospun poly( $\alpha$-hydroxy ester)-based fibrous scaffolds for tissue engineering applications. Acta Biomater. 2006, 2, 377-385. [CrossRef]

4. Puppi, D.; Chiellini, F.; Dash, M.; Chiellini, E. Biodegradable Polymers for Biomedical Applications. Nova Science Publishers: Hauppauge, NY, USA, 2011; pp. 545-604. ISBN 9781612095349.

5. Gunatillake, P.A.; Adhikari, R. Biodegradable synthetic polymers for tissue engineering. Eur. Cell. Mater. 2003, 5, 1-16. [CrossRef]

6. Pham, Q.P.; Sharma, U.; Mikos, A.G. Electrospinning of Polymeric Nanofibers for Tissue Engineering Applications: A Review. Tissue Eng. 2006, 12, 1197-1211. [CrossRef] [PubMed]

7. Braghirolli, D.I.; Steffens, D.; Pranke, P. Electrospinning for regenerative medicine: A review of the main topics. Drug Discov. Today 2014, 19, 743-753. [CrossRef] [PubMed]

8. Gil-Castell, O.; Badia, J.D.D.; Ribes-Greus, A. Tailored electrospun nanofibrous polycaprolactone/gelatin scaffolds into an acid hydrolytic solvent system. Eur. Polym. J. 2018, 101, 273-281. [CrossRef]

9. Ji, W.; Sun, Y.; Yang, F.; Van Den Beucken, J.J.J.P.; Fan, M.; Chen, Z.; Jansen, J.A. Bioactive electrospun scaffolds delivering growth factors and genes for tissue engineering applications. Pharm. Res. 2011, 28, 1259-1272. [CrossRef] [PubMed]

10. Gil-Castell, O.; Badia, J.D.; Ontoria-Oviedo, I.; Castellano, D.; Marco, B.; Rabal, A.; Bou, J.J.; Serra, A.; Monreal, L.; Blanes, M.; et al. In vitro validation of biomedical polyester-based scaffolds: Poly(lactide-co-glycolide) as model-case. Polym. Test. 2018, 66, 256-267.

11. Pereira, R.F.; Bártolo, P.J. Degradation Behavior of Biopolymer-based Membranes for Skin Tissue Regeneration. Procedia Eng. 2013, 59, 285-291. [CrossRef]

12. Venugopal, J.; Ramakrishna, S. Biocompatible Nanofiber Matrices for the Engineering of a Dermal Substitute for Skin Regeneration. Tissue Eng. 2005, 11, 847-854. [CrossRef]

13. Castellano, D.; Blanes, M.; Marco, B.; Cerrada, I.; Ruiz-Saurí, A.; Pelacho, B.; Araña, M.; Montero, J.A.; Cambra, V.; Prosper, F.; et al. A Comparison of Electrospun Polymers Reveals Poly(3-Hydroxybutyrate) Fiber as a Superior Scaffold for Cardiac Repair. Stem Cells Dev. 2014, 23, 1479-1490. [CrossRef] [PubMed]

14. Yu, J.; Lee, A.-R.; Lin, W.-H.; Lin, C.-W.; Wu, Y.-K.; Tsai, W.-B. Electrospun PLGA Fibers Incorporated with Functionalized Biomolecules for Cardiac Tissue Engineering. Tissue Eng. Part A 2014, 20, 1896-1907. [CrossRef] [PubMed]

15. Lakshmanan, R.; Maulik, N. Development of next generation cardiovascular therapeutics through bio-assisted nanotechnology. J. Biomed. Mater. Res. Part B Appl. Biomater. 2018, 106, 2072-2083. [CrossRef]

16. Yildirimer, L.; Seifalian, A.M. Three-dimensional biomaterial degradation-Material choice, design and extrinsic factor considerations. Biotechnol. Adv. 2014, 32, 984-999. [CrossRef] [PubMed]

17. O’Brien, F.J. Biomaterials $\{\&\}$ scaffolds for tissue engineering. Mater. Today 2011, 14, 88-95.

18. Badia, J.D.; Gil-Castell, O.; Ribes-Greus, A. Long-term properties and end-of-life of polymers from renewable resources. Polym. Degrad. Stab. 2017, 137, 35-57. [CrossRef] 
19. Huang, C.-H.; Lee, S.-Y.; Horng, S.; Guy, L.-G.; Yu, T.-B. In vitro and in vivo degradation of microfiber bioresorbable coronary scaffold. J. Biomed. Mater. Res. Part B Appl. Biomater. 2018, 106, 1842-1850. [CrossRef]

20. Hakkarainen, M.; Albertsson, A.-C.; Karlsson, S. Weight losses and molecular weight changes correlated with the evolution of hydroxyacids in simulated in vivo degradation of homo- and copolymers of PLA and PGA. Polym. Degrad. Stab. 1996, 52, 283-291. [CrossRef]

21. Göpferich, A. Mechanisms of polymer degradation and erosion. Biomaterials 1996, 17, 103-114. [CrossRef]

22. Sabino, M.A.; González, S.; Márquez, L.; Feijoo, J.L. Study of the hydrolytic degradation of polydioxanone PPDX. Polym. Degrad. Stab. 2000, 69, 209-216. [CrossRef]

23. Fouad, H.; Elsarnagawy, T.; Almajhdi, F.N.; Khalil, K.A. Preparation and In Vitro Thermo-Mechanical Characterization of Electrospun PLGA Nanofibers for Soft and Hard Tissue Replacement. Int. J. Electrochem. Sci. 2013, 8, 2293-2304.

24. You, Y.; Min, B.-M.; Lee, S.J.; Lee, T.S.; Park, W.H. In vitro degradation behavior of electrospun polyglycolide, polylactide, and poly(lactide-co-glycolide). J. Appl. Polym. Sci. 2005, 95, 193-200. [CrossRef]

25. Abhari, R.E.; Mouthuy, P.A.; Zargar, N.; Brown, C.; Carr, A. Effect of annealing on the mechanical properties and the degradation of electrospun polydioxanone filaments. J. Mech. Behav. Biomed. Mater. 2017, 67, 127-134. [CrossRef]

26. Bosworth, L.A.; Downes, S. Physicochemical characterisation of degrading polycaprolactone scaffolds. Polym. Degrad. Stab. 2010, 95, 2269-2276. [CrossRef]

27. Bonartsev, A.P.; Boskhomodgiev, A.P.; Iordanskii, A.L.; Bonartseva, G.A.; Rebrov, A.V.; Makhina, T.K.; Myshkina, V.L.; Yakovlev, S.A.; Filatova, E.A.; Ivanov, E.A.; et al. Hydrolytic Degradation of Poly(3-hydroxybutyrate), Polylactide and their Derivatives: Kinetics, Crystallinity, and Surface Morphology. Mol. Cryst. Liq. Cryst. 2012, 556, 288-300.

28. International Organization for Standardization. ISO 3696:1987. Water for Analytical Laboratory Use-Specification and Test Methods; Technical Committee ISO/TC 47: Geneva, Switzerland, 1987.

29. International Organization for Standardization. ISO 10993-13. Biological Evaluation of Medical Devices; Technical Committee ISO/TC 47: Geneva, Switzerland, 2010.

30. Ishikiriyama, K.; Pyda, M.; Zhang, G.; Forschner, T.; Grebowicz, J.; Wunderlich, B. Heat capacity of poly-p-dioxanone. J. Macromol. Sci. Part B 1998, 37, 27-44.

31. Mark, J.E. Properties of Polymers Handbook; Springer: Berlin, Germany, 2007.

32. Barham, P.J.; Keller, A.; Otun, E.L.; Holmes, P.A. Crystallization and morphology of a bacterial thermoplastic: poly-3-hydroxybutyrate. J. Mater. Sci. 1984, 19, 2781-2794. [CrossRef]

33. Jenkins, M.J.; Harrison, K.L. The effect of crystalline morphology on the degradation of polycaprolactone in a solution of phosphate buffer and lipase. Polym. Adv. Technol. 2008, 19, 1901-1906.

34. Cai, H.; Dave, V.; Gross, R.A.; McCarthy, S.P. Effects of physical aging, crystallinity, and orientation on the enzymatic degradation of poly(lactic acid). J. Polym. Sci. Part B Polym. Phys. 1996, 34, 2701-2708. [CrossRef]

35. Yoon, D.M.; Fisher, J.P. Natural and Synthetic Polymeric Scaffolds. In Biomedical Materials; Narayan, R., Ed.; Springer: Berlin, Germany, 2009; pp. 415-442. ISBN 9780387848716.

36. Vey, E.; Roger, C.; Meehan, L.; Booth, J.; Claybourn, M.; Miller, A.F.; Saiani, A. Degradation mechanism of poly(lactic-co-glycolic) acid block copolymer cast films in phosphate buffer solution. Polym. Degrad. Stab. 2008, 93, 1869-1876.

37. Díaz, E.; Sandonis, I.; Valle, M.B. In Vitro Degradation of Poly(caprolactone)/nHA Composites. J. Nanomater. 2014, 2014, 1-8. [CrossRef]

38. Höglund, A.; Hakkarainen, M.; Albertsson, A. Degradation Profile of Poly(€-caprolactone)-the Influence of Macroscopic and Macromolecular Biomaterial Design. J. Macromol. Sci. Part A 2007, 44, 1041-1046. [CrossRef]

39. Laeger, T.; Metges, C.C.; Kuhla, B. Role of $\beta$-hydroxybutyric acid in the central regulation of energy balance. Appetite 2010, 54, 450-455. [CrossRef]

40. Paşcu, E.I.; Stokes, J.; McGuinness, G.B. Electrospun composites of PHBV, silk fibroin and nano-hydroxyapatite for bone tissue engineering. Mater. Sci. Eng. C. Mater. Biol. Appl. 2013, 33, 4905-4916. [CrossRef]

41. Kim, K.; Yu, M.; Zong, X.; Chiu, J.; Fang, D.; Seo, Y.-S.; Hsiao, B.S.; Chu, B.; Hadjiargyrou, M. Control of degradation rate and hydrophilicity in electrospun non-woven poly (d,l-lactide) nanofiber scaffolds for biomedical applications. Biomaterials 2003, 24, 4977-4985. [CrossRef] 
42. Zong, X.; Ran, S.; Kim, K.S.; Fang, D.; Hsiao, B.S.; Chu, B. Structure and morphology changes during in vitro degradation of electrospun poly(glycolide-co-lactide) nanofiber membrane. Biomacromolecules 2003, 4, 416-423. [CrossRef]

43. Sabino, M.A.; Albuerne, J.; Müller, A.; Brisson, J.; Prud'homme, R.E. Influence of in vitro hydrolytic degradation on the morphology and crystallization behavior of poly(p-dioxanone). Biomacromolecules 2004, 5, 358-370. [CrossRef]

44. Chen, G.-Q.; Wu, Q. The application of polyhydroxyalkanoates as tissue engineering materials. Biomaterials 2005, 26, 6565-6578. [CrossRef]

45. Chanprateep, S. Current trends in biodegradable polyhydroxyalkanoates. J. Biosci. Bioeng. 2010, 110, 621-632. [CrossRef]

46. Wu, X.S.; Wang, N. Synthesis, characterization, biodegradation, and drug delivery application of biodegradable lactic/glycolic acid polymers. Part II: biodegradation. J. Biomater. Sci. Polym. Ed. 2001, 12, 21-34. [CrossRef]

47. Zhou, X.; Cai, Q.; Yan, N.; Deng, X.; Yang, X. In vitro hydrolytic and enzymatic degradation of nestlike-patterned electrospun poly(D,L-lactide-co-glycolide) scaffolds. J. Biomed. Mater. Res. Part A 2010, 95A, 755-765. [CrossRef]

48. Chen, D.R.; Bei, J.Z.; Wang, S.G. Polycaprolactone microparticles and their biodegradation. Polym. Degrad. Stab. 2000, 67, 455-459. [CrossRef]

49. Badia, J.D.; Vilaplana, F.; Karlsson, S.; Ribes-Greus, A. Thermal analysis as a quality tool for assessing the influence of thermo-mechanical degradation on recycled poly(ethylene terephthalate). Polym. Test. 2009, 28, 169-175. [CrossRef]

50. Santonja-Blasco, L.; Moriana, R.; Badía, J.D.; Ribes-Greus, A. Thermal analysis applied to the characterization of degradation in soil of polylactide: I. Calorimetric and viscoelastic analyses. Polym. Degrad. Stab. 2010, 95, 2185-2191. [CrossRef]

51. Badia, J.D.; Strömberg, E.; Karlsson, S.; Ribes-Greus, A. Material valorisation of amorphous polylactide. Influence of thermo-mechanical degradation on the morphology, segmental dynamics, thermal and mechanical performance. Polym. Degrad. Stab. 2012, 97, 670-678. [CrossRef]

52. Gil-Castell, O.; Badia, J.D.; Kittikorn, T.; Strömberg, E.; Ek, M.; Karlsson, S.; Ribes-Greus, A.; Strömberg, E.; Ek, M.; Karlsson, S.; et al. Impact of hydrothermal ageing on the thermal stability, morphology and viscoelastic performance of PLA/sisal biocomposites. Polym. Degrad. Stab. 2016, 132, 87-96. [CrossRef]

53. Badia, J.D.; Kittikorn, T.; Strömberg, E.; Santonja-Blasco, L.; Martínez-Felipe, A.; Ribes-Greus, A.; Ek, M.; Karlsson, S. Water absorption and hydrothermal performance of PHBV/sisal biocomposites. Polym. Degrad. Stab. 2014, 108, 166-174. [CrossRef]

54. Gil-Castell, O.; Badia, J.D.; Kittikorn, T.; Strömberg, E.; Martínez-Felipe, A.; Ek, M.; Karlsson, S.; Ribes-Greus, A. Hydrothermal ageing of polylactide/sisal biocomposites. Studies of water absorption behaviour and Physico-Chemical performance. Polym. Degrad. Stab. 2014, 108, 212-222. [CrossRef]

55. Badia, J.D.; Ribes-Greus, A. Mechanical recycling of polylactide, upgrading trends and combination of valorization techniques. Eur. Polym. J. 2016, 84, 22-39. [CrossRef]

56. Gil-Castell, O.; Badia, J.D.; Ribes-Greus, A. Suitability of blends from virgin and reprocessed polylactide: Performance and energy valorization kinetics. J. Renew. Mater. 2018, 6, 370-382. [CrossRef]

57. Badia, J.D.; Strömberg, E.; Karlsson, S.; Ribes-Greus, A. The role of crystalline, mobile amorphous and rigid amorphous fractions in the performance of recycled poly (ethylene terephthalate) (PET). Polym. Degrad. Stab. 2012, 97, 98-107. [CrossRef]

58. Badia, J.D.; Strömberg, E.; Kittikorn, T.; Ek, M.; Karlsson, S.; Ribes-Greus, A. Relevant factors for the eco-design of polylactide/sisal biocomposites to control biodegradation in soil in an end-of-life scenario. Polym. Degrad. Stab. 2017, 143, 9-19. [CrossRef]

59. Hoffman, J.D.; Lauritzen, J.I. Crystallization of Bulk Polymers with Chain Folding: Theory of Growth of Lamellar Spherulites. J. Res. Natl. Bur. Stand. A. Phys. Chem. 1961, 65, 1961. [CrossRef]

60. Lauritzen, J.I.; Hoffman, J.D. Formation of Polymer Crystals with Folded Chains from Dilute Solution. J. Chem. Phys. 1959, 31, 1680-1681. [CrossRef]

61. Engelberg, I.; Kohn, J. Physico-mechanical properties of degradable polymers used in medical applications: a comparative study. Biomaterials 1991, 12, 292-304. [CrossRef] 
62. Ping Ooi, C.; Cameron, R.E. The hydrolytic degradation of polydioxanone (PDSII) sutures. Part I: Morphological aspects. J. Biomed. Mater. Res. 2002, 63, 280-290. [CrossRef]

63. Gil-Castell, O.; Badia, J.D.D.; Strömberg, E.; Karlsson, S.; Ribes-Greus, A. Effect of the dissolution time into an acid hydrolytic solvent to tailor electrospun nanofibrous polycaprolactone scaffolds. Eur. Polym. J. 2017, 87, 174-187. [CrossRef]

64. Sultana, N.; Khan, T.H. In Vitro Degradation of PHBV Scaffolds and nHA/PHBV Composite Scaffolds Containing Hydroxyapatite Nanoparticles for Bone Tissue Engineering. J. Nanomater. 2012, 2012, 1-12.

(C) 2019 by the authors. Licensee MDPI, Basel, Switzerland. This article is an open access article distributed under the terms and conditions of the Creative Commons Attribution (CC BY) license (http://creativecommons.org/licenses/by/4.0/). 